\title{
ANÁlise do PERFIL dos discentes do CuRso TÉcnico SubSEQUente EM Eventos do IFPR - CAMPUS CWB: REFLEXões E PROPOSIÇÕES
}

\author{
ANALYSIS OF THE PROFILE OF THE STUDENTS OF THE SUBSEQUENT TECHNICAL \\ COURSE IN EVENTS OF THE IFPR - CWB CAMPUS: REFLECTIONS AND PROPOSITIONS \\ ANÁlisis DEL PERFIL DE LOS ESTUDIANTES DEL CURSO TÉCNICO POSTERIOR EN \\ EVENTOS DEL IFPR - CAMPUS CWB: REFLEXIONES Y PROPUESTAS
}

\author{
Mayna de Aquino \\ (iD) 9 \\ Mestre em Turismo (UFPR) \\ Professora substituta no Curso \\ Técnico Subsequente em Eventos \\ do IFPR - Campus Curitiba \\ mayna.aquino@ifpr.edu.br
}

Cássia Cristina Moretto da

Silva

(iD) 9

Doutorado em Meio Ambiente e

Desenvolvimento (UFPR)

Professora no Curso Técnico

Subsequente em Eventos do IFPR

- Campus Curitiba

cassia.silva@ifpr.edu.br

\section{Marco Aurelio Visintin \\ (iD) 9}

Mestre em Informática Industrial (CEFET-PR)

Professor no Curso Técnico

Subsequente em Eventos do IFPR

- Campus Curitiba

marco.visintin@ifpr.edu.br

\section{Luiz Ailil Vianna Martins (iD) 9}

Mestre em Turismo e Hotelaria (UNIVALI)

Professor no Curso Técnico

Subsequente em Eventos do IFPR

- Campus Curitiba

luiz.martins@ifpr.edu.br

\begin{abstract}
Resumo
A Educação Profissional se transformou estabelecendo-se como principal instrumento formativo, suprindo de capital humano qualificado demandas de mercados. No Brasil, o ensino técnico subsequente ao médio vislumbrou oportunidade nas Redes Federais de preparar profissionais às áreas de mercado sindicalizadas. Do reconhecimento das demandas de mercado à adequação de cursos e currículos, em IF's do país, percebeu-se que há pouca correlação entre a realidade e expectativa dos profissionais, quando da inserção no mundo do trabalho. O objetivo deste estudo foi analisar o Curso Técnico Subsequente em Eventos do Instituto Federal do Paraná - Campus Curitiba para compreender as realidades sociodemográficas, habilidades e expectativas de seus discentes em relação ao curso e, assim, relacionar sua oferta a demanda na adequação das expectativas à realidade. Com metodologia constituída de pesquisa qualitativaquantitativa obteve-se resultados capazes de propor adequações curriculares nas abordagens disciplinares do Projeto Pedagógico do Curso e, identificar desdobramentos para novas propostas formativas.
\end{abstract}

Palavras-chave: Perfil. Discentes. Ingressantes. Concluintes. Eventos.

Recebido em: 24 de março de 2021.

Aprovado em: 18 de julho de 2021.

Como citar esse artigo (ABNT):

AQUINO, Mayna de et al. Análise do perfil dos discentes do Curso Técnico Subsequente em Eventos do IFPR - Campus CWB: reflexões e proposições. Revista Prática Docente, v. 6, n. 2, e049, 2021.

http://doi.org/10.23926/RPD.2021.v6.n2.e049.id1059 


\section{Abstract}

The Professional Education has become established as the main training tool, supplying qualified human capital with market demands. In Brazil, technical education subsequent to high school saw an opportunity in the Federal Networks to prepare professionals for unionized market areas. From the recognition of market demands to the adequacy of courses and curricula, in the country's IF's, it was noticed that there is little correlation between the reality and expectations of professionals, when entering the world of work. The objective of this study was to analyze the Subsequent Technical Course in Events of the Federal Institute of Paraná - Campus Curitiba to understand the sociodemographic realities, skills and expectations of its students in relation to the course and, thus, relate its offer to demand in adapting expectations to reality. With a methodology consisting of qualitative and quantitative research, results were obtained that were able to propose curricular adjustments in the disciplinary approaches of the Pedagogical Course Project and to identify developments for new training proposals.

Keywords: Profile. Students. Newcomers. Finishers. Events.

\section{Resumen}

La Educación Profesional se ha consolidado como la principal herramienta de formación, aportando capital humano calificado con las demandas del mercado. En Brasil, la educación técnica posterior al bachillerato vio una oportunidad en las Redes Federales para preparar profesionales para áreas de mercado sindicalizado. Desde el reconocimiento de las demandas del mercado hasta la adecuación de los cursos y planes de estudio, en los IF's del país, se advirtió que existe poca correlación entre la realidad y las expectativas de los profesionales, al ingresar al mundo laboral. El objetivo de este estudio fue analizar el Curso Técnico Posterior en Eventos del Instituto Federal de Paraná Campus Curitiba para comprender las realidades sociodemográficas, habilidades y expectativas de sus estudiantes en relación al curso y, así, relacionar su oferta con la demanda en la adecuación de expectativas. a la realidad. Con una metodología consistente en investigación cualitativa y cuantitativa se obtuvieron resultados que permitieron proponer ajustes curriculares en los enfoques disciplinares del Proyecto Curso Pedagógico e identificar desarrollos para nuevas propuestas formativas.

Palabras clave: Perfil. Estudiantes. Recién llegados. Finalizadores. Eventos. 


\section{INTRODUÇÃ̃o}

A percepção docente em cursos Técnicos, no contexto de sala de aula, tem a capacidade de identificar questões a serem trabalhadas no estabelecimento de estratégias que visem o compromisso da qualidade na formação profissional discente. Motta (2014) afirma, em estudo que traçou o perfil do aluno de cursos Técnicos, que as matrículas nestes aumentaram mais de $70 \%$ entre os anos de 2002 a 2010 sendo fundamental uma observação atenta a este segmento educacional para retratar os discentes de cursos Técnicos, principalmente, após a instituição da Lei $\mathrm{n}^{\mathrm{o}} 11.741$ de 16 julho de 2008, que estabeleceu diretrizes e bases da educação profissional técnica de nível médio, da educação de jovens e adultos, da educação profissional e tecnológica desvinculando o Ensino Médio da Educação Profissional.

Neste sentido, os docentes do colegiado do Curso Técnico Subsequente em Eventos do Instituto Federal do Paraná (IFPR) - Campus Curitiba, curso este instituído em 2010, observaram uma demanda crescente de matrículas, à proporção de 15,5 discentes/ano nos anos de 2011 a 2018 (IFPR, 2019) e um comportamento recorrente entre seus discentes, principalmente nas Turmas 2019 e 2020, o aumento de ingressantes, na ordem de $30 \%$ com formação superior, o que representa aproximadamente, de 7 a 10 discentes, por turma. As hipóteses que poderiam responder a esta realidade observada seriam: o desejo destes discentes de se especializarem na área de eventos, este ser um curso gratuito, ampliar as oportunidades de inserção no mercado profissional, ou ainda, a baixa oferta de especializações gratuitas na área, em nível de pós-graduação Lato Sensu, na urbe de Curitiba e Região Metropolitana (RM).

Para compreender tal problema, os docentes deste colegiado estruturaram um formulário digital cuja pergunta norteadora foi: Qual o perfil sociodemográfico, as habilidades e interesses que motivaram os discentes, ingressantes e concluintes, do Curso Técnico Subsequente em Eventos, do IFPR - Campus Curitiba a fazerem o curso? Por meio de levantamento de dados qualitativos e quantitativos, tornou-se possível traçar o perfil dos discentes pertencentes às Turmas de 2019 e 2020 , concluintes ( $3^{\circ}$ semestre do ano letivo 2020$)$ e ingressantes $\left(1^{\circ}\right.$ semestre do ano letivo 2020), respectivamente, do Curso Técnico Subsequente em Eventos do IFPR Campus Curitiba.

Os temas de interesse deste colegiado são identificados e documentados em atas de reuniões mensais, gerando ações a serem realizadas em forma de projetos, de pesquisa e/ou extensão, como foi o caso desta temática que se apresentou como relevante quando um projeto de extensão paralelo estava sendo desenvolvido, cujo objetivo deste, era apresentar o Curso 
Técnico Subsequente em Eventos aos stakeholders locais (empresas organizadoras de eventos e associações do segmento) e, estabelecer relações que possibilitassem um melhor ingresso dos discentes, concluintes e ingressantes, no mercado de trabalho da área de Eventos em Curitiba e RM. O que justifica o interesse acadêmico deste colegiado em realizar esta investigação. Profissionalmente, o colegiado se motivou por meio das reflexões coletivas incentivadas pela Pró-Reitoria de Ensino (PROENS) e Direção de Ensino do IFPR - Campus Curitiba, em ação anual no evento da Semana Pedagógica - Formação Pedagógica e Planejamento Coletivo Edição 2020, realizado nos meses de fevereiro e julho do mesmo ano. A iniciativa visava a organização dos currículos dos cursos técnicos e as possibilidades de integração entre componentes curriculares objetivando melhores alternativas para Educação Profissional.

As informações coletadas tiveram o objetivo geral de analisar o perfil dos discentes, concluintes e ingressantes, do Curso Técnico Subsequente em Eventos, do IFPR - Campus Curitiba, para compreender suas realidades sociodemográficas, habilidades e expectativas em relação ao curso. De forma mais específica e direcionada, munidos dos resultados obtidos, tornou-se possível propor um planejamento estratégicos do curso com maior eficácia, sugerindo adequações às realidades identificadas visando: conhecer a realidade sociodemográfica dos discentes do curso, examinar se os conteúdos curriculares e abordagens disciplinares do Projeto Pedagógico do Curso (PPC) vigente estão de acordo com a realidade apresentada pelos discentes e, identificar a presença de demandas para desdobramentos de novas propostas formativas.

Proposta de investigações semelhantes já foram realizadas em instituições de ensino, públicas e privadas, algumas com o objetivo pós-formativo (analisando somente o perfil do egresso) e, outras, com um viés socioeconômico (BILERT e BISCOLI, 2011; SOARES, 2012; CARVALHO e REJOWSKI, 2012; MORAZ, 2015, BOSCARDIN ET. AL, 2016; SOUZA, MARTINS, MAIOLI, 2019). Este estudo é mais abrangente que os anteriores, pois, analisa o perfil sociodemográfico dos discentes cursantes, para identificar elementos de proposição de ações para melhorias durante a formação e pós-formação. Com base no referencial teórico construído para o projeto de pesquisa que deu origem a este artigo, verificou-se elementos que conferem a inediticidade deste projeto: ser estudo de natureza metodológica quali-quanti, apresentar perfil sociodemográfico, ter universo amostral composto por discentes concluintes e ingressantes, ser realizado por docentes do colegiado do curso, trazer a visibilidade de resultado de recorte temporal atual (2019-2020) e, ser direcionado à produção científica. 


\section{EducaÇão Profissional: do Ensino Industrial ao Ensino TÉCnico SubSEQUENTE} EM Eventos do IFPR - CAMPus CuRitiba, do MUNDO do Trabalho às OPORTUNIDADES

O marco teórico que dá início a esta discussão temática compreende o histórico da Educação Profissional no Brasil e, as inúmeras transformações ocorridas até a legislação que permitiu a modalidade Subsequente de Ensino Técnico no nível médio, em Redes Federais. De 1942, quando do Decreto n 4.073, "Lei Orgânica do Ensino Industrial” foi instituído, a segunda fase de expansão da abertura dos Institutos Federais de Educação (IF’s) até 2008, foram aproximadamente 70 anos de história da Educação Profissional em nosso país.

Em levantamento teórico realizado na plataforma do INEP, mais de 30\% dos estudos utilizados citam referências como: Kuenzer (2000, 2001), Cunha (2000), Moura (2007) e Araújo e Rodrigues (2011) quando abordam o histórico da Educação Profissional. Para apresentação de um panorama sucinto sobre a Educação Profissional, os autores acima confirmam, em seus estudos, que a Educação Profissional no Brasil surgiu no século XIX, aproximadamente no ano de 1809 com o Colégio das Fábricas, na cidade do Rio de Janeiro.

Para Moura (2007) e Xavier e Fernandes (2019), a Educação Profissional brasileira, nesta época, tinha como objetivo atender indivíduos que não tinham condições socioeconômicas razoáveis, destacando assim um papel assistencialista, em ofertar ensino público e gratuito na tentativa de projetar capital humano capacitado ao mundo do trabalho. $\mathrm{O}$ que em 1910 se confirma com o Decreto que fundou as Escolas de Aprendizes Artífices, permitindo que a classe proletária tivesse alternativas para obter sua subsistência.

Em 1930, a formação para a força de trabalho trouxe a compreensão dos caminhos pelos quais a Educação Profissional viria a tomar, devido a projetos do governo que visavam a modernização da sociedade brasileira (MACHADO, 2012). Nas décadas de 1930 e 1940 é que se institucionalizou a Educação Profissional no Brasil, considerando dois marcos relevantes: o "nascimento do Senai e das leis orgânicas do ensino em 1942, que foram respostas do Estado e dos empresários à então nova demanda por formação de trabalhadores" (ARAÚJO e RODRIGUES, 2011, p. 52 e 53).

Debates de uma comissão formada por indicados do governo que ocupavam cargos ligados ao ensino industrial ou postos dentro dos ministérios, criaram o Decreto ${ }^{\circ} 4.073$, de 30 
de janeiro de 1942, conhecido como "Lei Orgânica do Ensino Industrial" (TANGUY, $2002^{1}$ apud MACHADO, 2012, p. 102), que estabelecida a relação indissolúvel entre: a Educação Profissional e o mundo do trabalho.

Próximo à década de 1960, as Escolas Industriais e Técnicas foram transformadas em autarquias denominadas de Escolas Técnicas Federais, estas ganharam autonomia didática e de gestão.

Anos mais tarde, na década de 70, a Lei de Diretrizes e Bases (LDB) transforma a escola técnica-profissional em currículo de ensino de segundo grau, atual ensino médio e, as instituições de Rede Federal do Brasil, incluindo a do Paraná, chamadas de Centros Federais de Educação Tecnológica (CEFET's) começaram a formar técnicos e engenheiros (ROCHAPINTO e BEZERRA, 2014).

Segundo o documento do Centenário da Rede Federal de Educação Profissional e Tecnológica (2009), entre a década de 1990 e os anos 2010, duas leis e um decreto foram relevantes para expansão do Ensino Técnico em Redes Federais: 1) a Lei no 8.948 de 1994 que levou em conta a estrutura física e às condições técnico-pedagógicas e administrativas (recursos humanos e financeiros) para funcionamento destas escolas; 2) a Lei no 9.394 de 1996 que superou o enfoque de assistencialista contido nas primeiras legislações de Educação Profissional do país, fazendo deste um mecanismo para favorecer a inclusão social e democratização dos bens sociais à sociedade; e, por fim, 3) o Decreto nº 2.208 de 1997 que regulamentou a Educação Profissional criando o Programa de Expansão da Educação Profissional (PROEP).

Assim, com o processo de transformação das Escolas Técnicas Federais em CEFET's concluído, permitiu que no ano de 2005 fosse publicada a Lei ${ }^{\circ} 11.195$ que lança a primeira fase do Plano de Expansão da Rede Federal de Educação Profissional e Tecnológica, construindo 64 novas unidades de ensino incluindo a transformação do CEFET - Paraná em Universidade Tecnológica Federal do Paraná (UTFPR) reconhecida como a primeira universidade especializada nessa modalidade de ensino no Brasil.

Diante de todas essas mudanças e expansões, os CEFET's e Escolas Técnicas Federais também sofreram modificações. Com a Lei n ${ }^{\circ} 11.892$, de 29 de dezembro de 2008, são criados os Institutos Federais de Educação Ciência e Tecnologia (IF's) em substituição aos CEFET's e

\footnotetext{
1 TANGUY, L. Um movimento social para a formação permanente na França, 1945-1970. Pro-Posições, Campinas, v. 13, n. 1, p. 18-33, jan./abr. 2002.
} 
escolas técnicas (BRASIL, 2008b; MENDONÇA, 2014). Foram criados 38 IF's em todo o Brasil. A princípio, a proposta político-pedagógica dos IF’s eram de: ofertar educação básica, educação profissional técnica de nível médio, ensino técnico em geral; graduações tecnológicas, licenciatura e bacharelado em áreas em que a ciência e a tecnologia (preponderantes às engenharias); programas de pós-graduação Lato Sensu e Stricto Sensu e; assegurar a formação inicial e continuada de trabalhadores (ANDRADE e CRUZ, 2016).

O IFPR, um destes 38 IF's, teve sua origem em uma escola técnica chamada Academia de Comércio Progresso vincula à Universidade Federal do Paraná (UFPR), pela Faculdade de Direito. Posteriormente, passou a ser vinculada ao Setor de Ciência Sociais Aplicadas denominando-a de Escola Técnica de Comércio da Universidade Federal do Paraná e, somente em 2008, passou a ser uma escola técnica federal independente (IFPR, 2020).

Em 2008, com a Lei no 11.741 é que se confirma a possibilidade de atuação da Educação Profissional desvinculado do ensino médio como alternativa para o pós-médio.

A Educação Técnica Profissional Subsequente em IF's passou a ser uma alternativa aos estudantes egressos de ensino médio que não optassem por ingressar no ensino superior, pois, "parece que ele recuperou a ideia de que os cursos técnicos fossem uma compensação para os concluintes do ensino médio que não conseguissem ingressar em um curso superior" (KUENZER, 2001, p. 98).

A Educação Profissional no Ensino Técnico Subsequente em IF’s isoladamente representam 18,7\% do total, 39.775 matrículas, no ano de 2019 (INEP, 2019). Números expressivos para subjugar os cursos Técnicos Subsequentes a apenas uma opção ao ensino superior. Com o aumento das matrículas no Ensino Técnico Subsequente em Redes Federais, IF's, amplia-se os recursos de formação profissional opcional aos estudantes e a oportunidade de formação técnica-profissional. O perfil destes estudantes de Educação Profissional é composto predominantemente por indivíduos do gênero feminino, entre 18 e 19 e entre 20 e 29 anos. Dados relevantes, porém, insuficientes para direcionar ações de planejamento estratégico para cursos específicos (INEP, 2019).

Se considerar as oportunidades de cursos Técnicos em Eventos em IF’s do Brasil, são 14 ofertas e, nestas, é perceptível que a maioria, 10 cursos, são de cursos Técnicos Subsequentes. Destes, 7, tem 1 ano e 6 meses de duração. Destaca-se que as suas alocações são em regiões distintas do país e consideradas destinos turísticos, conforme quadro 1, abaixo: 
Quadro 1 - Cursos Técnicos em Eventos em nível médio

\begin{tabular}{|c|c|c|c|c|c|c|}
\hline Oferta & Modalidade & Nomenclatura & Nível médio & Duração & IF & Campus \\
\hline 1 & Presencial & \multirow{3}{*}{$\begin{array}{l}\text { Técnico em } \\
\text { Eventos }\end{array}$} & Subsequente & 1 ano & Ceará/ CE & Acaraú \\
\hline 2 & Presencial & & Integrado & \multirow{2}{*}{$\begin{array}{l}1 \text { ano e } \\
6 \text { meses }\end{array}$} & São Paulo/ SP & Avaré \\
\hline 3 & Presencial & & Subsequente & & São Paulo/ SP & Barretos \\
\hline 4 & Presencial & & $\begin{array}{l}\text { Subsequente/ } \\
\text { Concomitante }\end{array}$ & & $\begin{array}{l}\text { Minas Gerais/ } \\
\text { MG }\end{array}$ & $\begin{array}{l}\text { Belo } \\
\text { Horizonte }\end{array}$ \\
\hline 5 & $\mathrm{EaD}$ & & Subsequente & & Fluminense/ RJ & Cabo Frio \\
\hline 6 & Presencial & & Integrado & 4 anos & $\begin{array}{l}\text { Rio Grande do } \\
\text { Norte/ RN }\end{array}$ & $\begin{array}{l}\text { Canguaretama } \\
\text {-Natal }\end{array}$ \\
\hline 7 & Presencial & $\begin{array}{l}\text { Técnico } \\
\text { Subsequente em } \\
\text { Eventos }\end{array}$ & Subsequente & \multirow{3}{*}{$\begin{array}{l}1 \text { ano e } \\
6 \text { meses }\end{array}$} & $\begin{array}{l}\text { Rio Grande do } \\
\text { Norte/ RN }\end{array}$ & $\begin{array}{l}\text { Canguaretama } \\
\text {-Natal }\end{array}$ \\
\hline 8 & $\mathrm{EaD}$ & $\begin{array}{l}\text { Técnico em } \\
\text { Eventos }\end{array}$ & Subsequente & & Fluminense/ RJ & $\begin{array}{l}\text { Campos } \\
\text { Centro }\end{array}$ \\
\hline 9 & Presencial & $\begin{array}{l}\text { Técnico } \\
\text { Subsequente em } \\
\text { Eventos }\end{array}$ & Subsequente & & Paraná/ PR & Curitiba \\
\hline 10 & Presencial & $\begin{array}{l}\text { Técnico em } \\
\text { Eventos }\end{array}$ & Subsequente & 1 ano & $\begin{array}{l}\text { Santa Catarina/ } \\
\text { SC }\end{array}$ & $\begin{array}{l}\text { Florianópolis- } \\
\text { Continente }\end{array}$ \\
\hline 11 & Presencial & $\begin{array}{l}\text { Técnico } \\
\text { Subsequente em } \\
\text { Eventos }\end{array}$ & Subsequente & $\begin{array}{l}1 \text { ano e } \\
6 \text { meses }\end{array}$ & $\begin{array}{l}\text { Rio Grande do } \\
\text { Sul/ RS }\end{array}$ & Osório \\
\hline 12 & Presencial & \multirow{3}{*}{$\begin{array}{l}\text { Técnico em } \\
\text { Eventos }\end{array}$} & Integrado & \multirow{2}{*}{3 anos } & Tocantins/ TO & Palmas \\
\hline 13 & Presencial & & Integrado & & Farroupilha/ RS & São Borja \\
\hline 14 & Presencial & & Subsequente & $\begin{array}{l}1 \text { ano e } \\
6 \text { meses }\end{array}$ & Farroupilha/ RS & São Borja \\
\hline
\end{tabular}

Fonte: Adaptado de IFSP (2012, 2014); IFFluminense (2012); IFFarroupilha (2014); IFRN (2014); IFCE (2015); IFTO (2015); IFMG (2016); IFRS (2016); IFSP (2016); IFSC (2017); IFPR (2014).

A maioria destes cursos foram instituídos a partir de 2010. Sob análise dos PPC's não foram encontradas informações sobre o perfil dos estudantes (concluintes e ingressantes), mas, todos eles trazem o perfil de egresso ou do profissional, exceto o PPC do IFFluminense - Campi Cabo Frio e Campos Centro. Além disto, todos trazem as informações dos números de matrículas ou progressões anuais, para conhecer o aumento da demanda. Todos estes apresentam como justificativa de abertura dos cursos as demandas turísticas locais, ou seja, onde os cursos foram instituídos, considerou-se como destinos turísticos em potencial e, por este motivo, a necessidade de abertura da oferta para preparar profissionais a suprirem o segmento de turismo de eventos dos mercados locais.

Quanto aos conhecimentos, todos apresentam formação profissional com competências específicas da área em sua estrutura, como: fundamentos ou introdução a eventos, planejamento de eventos, cerimonial e protocolo, alimentos e bebidas, segurança para eventos, legislação para eventos e gestão financeira para eventos; apenas denominados diferentemente e, obviamente, níveis distintos de aprofundamento. Os componentes curriculares da formação geral, chamados de conhecimentos universalizantes como: idiomas (inglês e espanhol) e TIC's (informática), 
todos apresentam, exceto o Curso de Técnico Subsequente em Eventos do IFPR - Campus Curitiba, que alterou seu PPC em 2019 e, mudou sua grade curricular que era de 1 ano e 6 meses para 1 ano, retirando estes componentes curriculares. Destes, apenas dois apresentam elaboração de projeto ao final do curso (IFSP, 2014; IFFluminense, 2012; IFFarroupilha, 2014; IFRN, 2014; IFRS, 2016; IFPR, 2019). Conforme o quadro 2, a seguir:

Quadro 2 - Componentes Curriculares dos cursos Técnico Subsequente em Eventos de IF's

\begin{tabular}{|c|c|c|c|c|c|c|c|}
\hline Modalidade & Duração & IF & Campus & Competências & Idiomas & TIC & $\begin{array}{c}\text { Elaboração } \\
\text { de Projeto }\end{array}$ \\
\hline Presencial & \multirow{4}{*}{$\begin{array}{l}1 \text { ano e } \\
6 \text { meses }\end{array}$} & São Paulo/ SP & Barretos & \multirow{7}{*}{ Sim } & Inglês & \multirow{4}{*}{ Sim } & Sim \\
\hline $\mathrm{EaD}$ & & $\begin{array}{l}\text { Fluminense/ } \\
\text { RJ }\end{array}$ & $\begin{array}{l}\text { Cabo } \\
\text { Frio }\end{array}$ & & $\begin{array}{l}\text { Inglês } \\
\text { Espanhol }\end{array}$ & & \multirow{3}{*}{ Não } \\
\hline Presencial & & $\begin{array}{l}\text { Rio Grande do } \\
\text { Norte/ RN }\end{array}$ & $\begin{array}{l}\text { Canguare } \\
\text { tama- } \\
\text { Natal }\end{array}$ & & Inglês & & \\
\hline $\mathrm{EaD}$ & & $\begin{array}{l}\text { Fluminense/ } \\
\text { RJ }\end{array}$ & $\begin{array}{l}\text { Campos } \\
\text { Centro }\end{array}$ & & $\begin{array}{l}\text { Inglês } \\
\text { Espanhol }\end{array}$ & & \\
\hline Presencial & 1 ano & Paraná/ PR & Curitiba & & Espanhol & Não & Não \\
\hline Presencial & \multirow{2}{*}{$\begin{array}{l}1 \text { ano e } \\
6 \text { meses }\end{array}$} & $\begin{array}{l}\text { Rio Grande do } \\
\text { Sul/ RS }\end{array}$ & Osório & & Não & \multirow{2}{*}{ Sim } & Não \\
\hline Presencial & & $\begin{array}{l}\text { Farroupilha/ } \\
\text { RS }\end{array}$ & $\begin{array}{l}\text { São } \\
\text { Borja }\end{array}$ & & $\begin{array}{l}\text { Inglês } \\
\text { Espanhol }\end{array}$ & & Sim \\
\hline
\end{tabular}

Fonte: Adaptado de IFSP (2012, 2014); IFFluminense (2012); IFFarroupilha (2014); IFRN (2014); IFCE (2015); IFTO (2015); IFMG (2016); IFRS (2016); IFSP (2016); IFSC (2017); IFPR (2019).

Sob análise do quadro 2 acima é perceptível que o único curso destoa dos demais: o do IFPR - Campus Curitiba visto que reduziu sua grade curricular para 1 ano, retirou componentes curriculares de formação geral como: TIC's e oferece apenas um idioma, que não é o inglês, como os demais. Para Silva e Guedes (2018) a base de um modelo de Ensino Técnico está na compreensão de que se deve dar importância às competências bem como a diversificação dos meios de aprendizagem articulando teoria e prática, transmitindo conhecimentos sistematizados das diversas áreas da formação humana.

Assim, o Curso Técnico Subsequente em Eventos do IFPR - Campus Curitiba suprimiu componentes curriculares importantes para formação geral, humana e universalista como o idioma de inglês e TIC's. Esta situação se torna relevante de debate quando os mundos: da Educação e do Trabalho se encontram e evidenciam que a formação profissional destes discentes não está condizente às realidades analisadas. Para Oliveira (2000, p. 45), o Ensino Técnico ministrado nas escolas técnicas “destina-se à habilitação profissional para Alunos 
egressos do Ensino Médio ou matriculados neste" (OLIVEIRA, 2000, p. $457^{2}$ apud LINS e MIYATA, 2008). O que significa que o Ensino Técnico deve preparar discentes para uma ampla atuação de mercado e, entende-se que idiomas (inglês) e TIC's tornam-se componentes complementares da formação para o mundo do trabalho.

O Curso Técnico Subsequente em Eventos do IFPR - Campus Curitiba completou 10 anos de atividades com 8 turmas formadas, pois, a primeira se formou no ano de 2011 e, no ano de 2014 não formou turma e, bem como os demais, justifica sua abertura devido às ofertas de turismo de eventos em Curitiba e RM e, seu objetivo é habilitar profissionais "com uma ampla gama de conhecimentos para a realização das etapas de um evento" (IFPR, 2019, p. 9).

Segundo estudo de Aquino e Teles (2019), as autoras apresentam o perfil do promotor de eventos segundo aspectos sociodemográficos e profissionais, destes, em Curitiba e RM:

[...] mulheres, entre 26 e 30 anos, solteiras, residentes de Curitiba, formadas em curso superior de marketing e/ou publicidade que são fluentes em inglês, espanhol e/ou são bilíngues nos dois idiomas, contratadas como recepcionistas, coordenadoras e produtoras, entre outros, que têm entre 5 e 10 anos de atividade profissional na área de eventos, que são terceirizadas contratadas por empresas organizadoras de eventos, tendo rendimentos mensais médios de $\mathrm{R} \$ 1.431,00$ (1 a 3 salários mínimos). Estas atuavam em atividades diversas, antes de trabalhar com eventos, em algumas áreas como guia de turismo bilíngue, hotelaria, secretária e etc. e que optaram trabalhar com eventos porque lhes permite dias livres para organizar a vida pessoal, sendo contratadas nos últimos 4 anos, primordialmente, por redes sociais e aplicativos de contato e indicação de amigos, geralmente, sendo contratadas para trabalhar na cidade de Curitiba (AQUINO e TELES, 2019, p. 101).

O mercado de trabalho da área de eventos está sendo ocupado pelos profissionais descritos acima, mas, deveria ser ocupado por profissionais egressos do Curso Técnico Subsequente em Eventos do IFPR - Campus Curitiba visto que em Relatório da Gestão 20112014 do Curitiba Convention \& Visitors Bureau, a organização captou 27 eventos nacionais e internacionais, no ano de 2014, mobilizando 335 promotores de eventos, no mesmo ano. No período da Gestão 2011-2014 que representa o início das atividades da associação no Paraná e, coincide com período em que o Curso se estabeleceu, foram realizados cerca 1.200 eventos, gerando uma receita de mais de $\mathrm{R} \$ 1,4$ bilhão. Estes eventos tiveram em média 311 apoiadores e sua maioria $(75 \%)$ eram do tipo técnico-científicos e, apenas $2 \%$ esportivos e sociais (CC\&VB, 2014).

Toda a movimentação econômica do segmento em Curitiba e RM, no que consiste a contratação de serviços complementares e de suporte e, o engajamento das empresas

\footnotetext{
${ }^{2}$ OLIVEIRA, M. R. N. S. Mudanças no mundo do trabalho: acertos e desacertos na proposta curricular para o Ensino Médio (Resolução CNE 03/98): diferenças entre formação técnica e formação tecnológica. Educação e Sociedade, Campinas, ano 21, n. 70, p. 40-62, abr. 2000.
} 
promotoras e organizadoras de eventos, para obtenção de êxito na execução dos eventos captados pelo CC\&VB, imputa qualificação adequada de profissionais interessados em trabalhar no segmento. Por este motivo, a preocupação com as adequações curriculares do curso, justificando esta análise deste estudo.

\section{MÉtodos E MATERIAIS}

Os métodos utilizados nesta investigação são descritos nas publicações de Creswell $(2010,2014)$ que define o que é e como se desenvolvem pesquisas qualitativas e quantitativas.

Assim, a pesquisa se desenvolveu cumprindo um caráter investigativo qualitativo e quantitativo fazendo uso de procedimentos metodológicos teórico-exploratório, por meio de pesquisa bibliográfica e documental e, empírico-analítico, com pesquisa aplicada em campo, facilitada por formulário digital. A metodologia foi desenvolvida pelos autores para realização de um projeto de pesquisa ${ }^{3}$, pois, o presente artigo apresenta os resultados das análises e interpretações deste.

Figura 1 - Percurso do processo metodológico

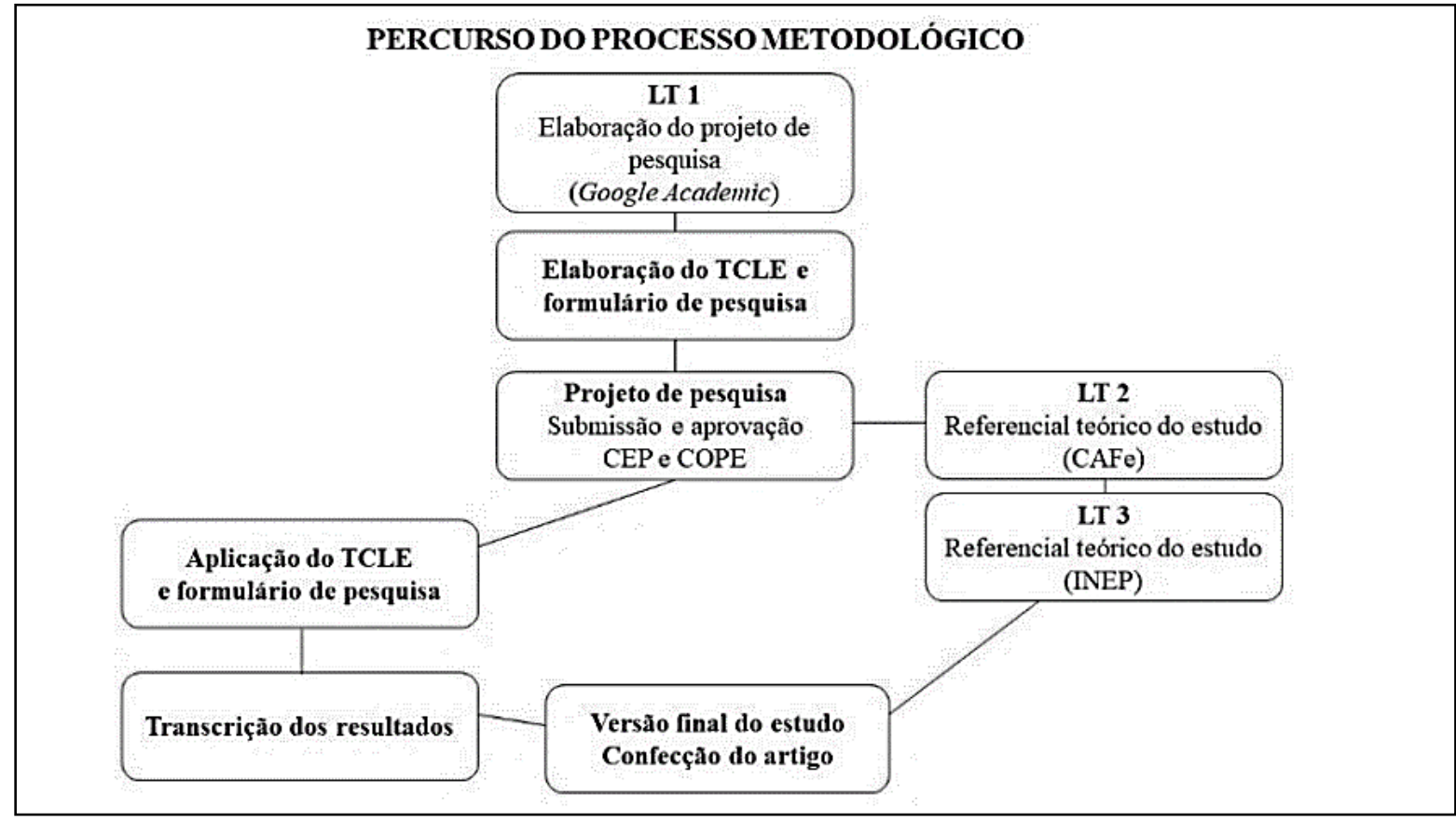

Fonte: Os autores (2021).

Legenda: $\mathrm{LT}=$ Levantamento teórico.

\footnotetext{
${ }^{3}$ O projeto de pesquisa intitulado: Estudo Analítico do Perfil dos Discentes do Curso Técnico Subsequente em Eventos do IFPR - Campus Curitiba: Turma 2019 e 2020 teve aprovação pelo Comitê de Pesquisa e Extensão do IFPR - Campus Curitiba sob o parecer SEI 23411.003899/2020-38 e pelo Comitê de Ética em Pesquisa do IFPR sob o Parecer: 3.993.431. Para ambos departamentos, estruturou-se um projeto detalhado determinando o compromisso dos autores e concordância da Instituição para realização da pesquisa, cumprindo todas exigências e requisitos solicitados.
} 
O levantamento de dados foi realizado com pesquisa teórico-exploratório, por meio de pesquisa bibliográfica e documental, para elaboração do projeto de pesquisa (introdução e referencial teórico) que sustentou as argumentações das discussões dos resultados. Foram realizados três levantamentos teóricos em plataformas distintas, como consta na figura 1 , realizados em datas diferentes, com termos de buscas pré-definidos, com ou sem recorte temporal, de acordo com o objetivo de cada busca. A validação dos estudos se deu por meio de leitura dos resumos, para identificação de aderência do estudo ao tema e, posteriormente, leitura na íntegra para utilização dos trechos (citações diretas e indiretas). Foi gerada uma planilha para listar os estudos encontrados e utilizados no projeto. Foram selecionados para utilização na introdução e referencial teórico: 7 estudos do Google Academic, nenhum do CAFe e 10 do INEP. A base documental e dados estatísticos foram resgatados de citações destes estudos e, por meio de acesso direto às fontes online.

Na sequência, estruturou-se dois formulários digitais: um para identificar os voluntários interessados a contribuírem com suas informações, por meio do Termo de Consentimento Livre e Esclarecido (TCLE) e, outro, para levantamento empírico-analítico dos dados quali-quanti inerentes à pesquisa de campo. O recurso material utilizado para elaboração de ambos foi a ferramenta Google Forms. Os participantes da pesquisa foram abordados pelos docentes, componentes do corpo técnico-científico desta pesquisa, via e-mail da turma ${ }^{4}$, endereço de emails individuais e, também pelo grupo de whatsapp 5 .

O TCLE assinado pelos docentes constando os objetivos da pesquisa e os procedimentos; os riscos e benefícios; a garantia da liberdade para retirar o consentimento; a garantia do sigilo; a garantia de acesso aos resultados e o contato dos pesquisadores ${ }^{6}$ foi disponibilizado virtualmente por meio de um formulário, destinando um campo para que os participantes assinalassem seu consentimento de participação na pesquisa e sua autorização de reprodução dos trechos. Assim, coletou-se os emails de contato dos voluntários interessado que se disponibilizaram a participar deste estudo, pertencentes a Turma 2019 e a Turma 2020.

O formulário digital, questionário estruturado para aplicação da pesquisa de campo, foi composto por 3 seções: sociodemográfico, habilidades e informações pertinentes ao curso. Nestas havia 23 questões sendo: 14 fechadas (quantitativas), 7 semiabertas (quali-quanti) e 2

\footnotetext{
${ }^{4}$ Recurso pelo qual os docentes concentram as informações oficiais para repassarem às turmas.

${ }^{5}$ Os discentes seriam abordados em horários de aulas, dado a pandemia de COVID-19, o procedimento teve que ser adaptado.

${ }^{6} \mathrm{O}$ TCLE seria impresso e, entregue aos indivíduos que tivessem interesse em participar da pesquisa, antes do preenchimento do formulário, mas, devido a pandemia de COVID-19 o procedimento teve que ser adaptado.
} 
abertas (qualitativas) cujo intuito era atingir os objetivos gerais e específicos desta pesquisa, estas foram mescladas, aleatoriamente. O tempo médio de preenchimento do formulário era de 2 minutos.

Os autores determinaram os limites da pesquisa. Delinearam o universo amostral, definindo que os participantes da pesquisa seriam os discentes das Turmas 2019 e 2020 do Curso Técnico Subsequente em Eventos do IFPR - Campus Curitiba. Este universo é composto por uma população de 52 indivíduos, sendo que destes, 23 discentes pertencem a Turma 2019 e, 29 da Turma 2020, dados da data de realização da pesquisa.

Nos critérios de inclusão e exclusão estipulou-se que todos os 52 indivíduos da população seriam abordados para se voluntariar a participar da pesquisa, porém, somente seriam válidas as participações daqueles discentes que estivessem regularmente matriculados no Curso Técnico Subsequente em Eventos, nas respectivas turmas. Desta forma, seriam descartados os TCLE's de discentes que constam na planilha de frequência do $\operatorname{SIGAA}^{7}$ como matriculado regularmente, mas, que não são frequentes nas disciplinas do semestre matriculado; bem como, os discentes em que fosse perceptível o acesso a informações privilegiadas, como os representantes de turma que participam de algumas das reuniões de colegiado.

Os recursos materiais utilizados foram basicamente os de meio virtual via internet como: email, whatsapp, Google Forms devido às implicações sanitárias que impuseram o isolamento social dada a pandemia de COVID-19 e a consequente suspensão das atividades presenciais de ensino. Para que fosse possível responder ao formulário, os participantes deveriam acessar os recursos materiais pessoais ${ }^{8}$ como: computadores, notebooks, tablets ou celulares (smartphones), com conexão à internet.

O projeto de pesquisa se desenvolveu de 28 de fevereiro de 2020 à 28 de fevereiro de 2021, em sua maior parte, durante o período de suspensão das atividades acadêmicas presenciais que ocorreu entre 17 de março de 2020 e 31 de março de 2021.

\section{APRESENTAÇÃO E DISCUSSÃO DOS RESULTADOS}

Os dados aqui apresentados são resultados do projeto de pesquisa que gerou 1 tabela para cada variável analisada nas 23 questões do formulário aplicado discriminando as turmas.

\footnotetext{
${ }^{7}$ Sistema Integrado de Gestão de Atividades Acadêmicas.

${ }^{8} \mathrm{O}$ projeto de pesquisa previa que, os discentes que não dispunham destes recursos materiais em suas residências pudessem comparecer, em datas e horários preestabelecidos ao Campus Curitiba e disporem dos recursos necessários ao preenchimento do formulário. Porém, dado a pandemia de COVID-19 essa alternativa não pode ser efetivada. $\mathrm{O}$ formulário foi disponibilizado online àqueles que dispusessem de recursos materiais próprios.
} 
Infelizmente, este modelo de artigo, não permite apresentar todas as 23 tabelas geradas, mas, estas estão à disposição para serem compartilhadas e, poderão ser solicitadas aos autores por email. O que será apresentado aqui são as considerações sobre as variáveis analisadas e o quadro resumo com o resultado final da pesquisa para facilitar as discussões.

O período de aplicação do TCLE, para identificar os voluntários da pesquisa, ocorreu entre os dias 24 a 31 de julho de 2020 (7 dias), obtendo 34 voluntários para esta análise e interpretação, sendo destes $16(47,00 \%)$ dos participantes pertencentes a Turma 2019, $3^{\circ}$ semestre (concluintes) e $18(53,00 \%)$ da Turma $20201^{\circ}$ semestre (ingressantes).

A aplicação do formulário da pesquisa se deu entre os dias 01 a 26 de agosto de 2020 (25 dias), obtendo 34 respondentes, os mesmos que se voluntariaram pelo TCLE. Destes 15 $(44,00 \%)$ se declaram pertencer a Turma 2019 e $19(56,00 \%)$ pertencentes a Turma 2020.

Despretensiosamente, o TCLE se tornou um instrumento de validação dos dados, pois, acredita-se ter havido falha na marcação ou na interpretação da questão que identifica à qual turma o discente pertence, por parte de algum participante e, como o formulário é anônimo, não foi possível identificá-lo. A responsabilidade de interpretação e preenchimento do formulário da pesquisa é única e exclusivamente do participante. O link para a pesquisa foi enviado exclusivamente ao email e, contato de whastapp, dos voluntários identificados no TCLE, não se cogita a possibilidade de vazamento do link, visto que o número de participantes é exatamente o mesmo de voluntários do TCLE.

Mediante análises do TCLE, todos os voluntários estavam aptos a participarem da pesquisa conforme às delimitações da pesquisa, não se invalidou nenhum dos instrumentos de coleta. Os resultados apresentados foram feitos conforme constam no preenchimento do formulário de pesquisa aplicada aos participantes, desta forma, esta amostra representa 65,38\% da população de discentes regularmente matriculados no curso, em ambas as turmas, sendo 65,22\% dos discentes da Turma 2019 e 65,52\% dos discentes da Turma 2020.

Os resultados serão apresentados em frequências absolutas, números inteiros seguidos por suas frequências relativas, valores percentuais, com a representação de duas casas decimais, após a vírgula. Ressalta-se que o grau de confiança estatística dos dados apresentados nesta pesquisa está em $95,00 \%$, tendo $10,00^{9}$ pontos percentuais de margem de erro, valor que absorve o único indivíduo que alterou a marcação na interpretação da questão que identifica a qual turma o discente pertence e, os 18 indivíduos restantes, de ambas as turmas, que não

\footnotetext{
${ }^{9}$ Cálculo realizado no site Survey Monkey. Disponível em: encurtador.com.br/buxH4. Acesso em 26 ago. 2020.
} 
tiveram interesse em participar da pesquisa. Os cálculos foram realizados pelos próprios autores com auxílio do gráfico dinâmico do Excel, onde uma planilha com os dados foi gerada para tabulação.

A apresentação dos resultados foi dividida nas 3 seções propostas para esta análise e interpretação e ao final apresenta-se o perfil analítico do discente do Curso Técnico Subsequente em Eventos do IFPR - Campus Curitiba. Na seção 1, as questões obtiveram o perfil sociodemográfico dos discentes de ambas as turmas e os dados foram confrontados com os do INEP (2019). Na seção 2, identificou as habilidades dos discentes contrapondo-se ao estudo do perfil sociodemográfico e profissional do promotor de eventos de Aquino e Teles (2019) e aos PPC's dos cursos Técnico em Eventos de IF's. Na seção 3, e última, apresentou aos interesses e expectativas que motivaram os discentes a realizarem o curso dimensionando os tipos de eventos existentes demonstrativos/expositivos, dialogais, competitivos, homenagem e sociais/coloquiais, de acordo com o Manual de Eventos da CNI (2015).

Para responder à pergunta problema e cumprir ao objetivo geral deste estudo apresentase o quadro 3, elaborado a partir dos dados obtidos na pesquisa de campo, com o perfil analítico dos discentes do Curso Técnico Subsequente em Eventos do IFPR - Campus Curitiba: Turmas 2019 e 2020, facilitando a interpretação de forma didática e favorecendo a discussão dos resultados logo a seguir:

Quadro 3 - Perfil dos discentes do Curso Técnico Subsequente em Eventos do IFPR - Campus Curitiba: Turmas 2019 e 2020

\begin{tabular}{|c|c|c|c|c|}
\hline Questões & Seção & Variável analisada & Resultado & Quant. \\
\hline 1 & \multirow{13}{*}{$\begin{array}{l}1 . \\
\text { Sociodemográfica }\end{array}$} & Gênero & Feminino & $29(85,00 \%)$ \\
\hline 2 & & Idade & Entre 17 a 24 anos & $15(44,00 \%)$ \\
\hline 3 & & Estado civil & Solteira & $23(68,00 \%)$ \\
\hline 4 & & Onde reside & Curitiba & $24(71,00 \%)$ \\
\hline 5 & & $\mathrm{RM}$ & $\begin{array}{l}\text { São José dos } \\
\text { Pinhais }\end{array}$ & $3(30,00 \%)$ \\
\hline 6 & & Escolaridade completa & Ensino médio & $20(59,00 \%)$ \\
\hline 7 & & $\begin{array}{l}\text { Os que tem curso de ensino } \\
\text { superior }\end{array}$ & $\begin{array}{l}\text { Publicidade e } \\
\text { Propaganda }\end{array}$ & $3(22,00 \%)$ \\
\hline 8 & & Trabalha com eventos & Não & $24(70,00 \%)$ \\
\hline 9 & & $\begin{array}{l}\text { Os que trabalham com eventos } \\
\text { cargo que exercem }\end{array}$ & Produção & $4(40,00 \%)$ \\
\hline 10 & & Os que trabalham com eventos têm & De 1 a 5 anos & $5(50,00 \%)$ \\
\hline 11 & & Os que não trabalham com eventos & $\begin{array}{l}\text { Administrativa/ } \\
\text { Financeira/RH } \\
\text { (Auxiliar ou } \\
\text { Analista) }\end{array}$ & $5(25,00 \%)$ \\
\hline 12 & & Condição profissional & $\begin{array}{l}\text { Profissional } \\
\text { contratado por CLT }\end{array}$ & $13(37,00 \%)$ \\
\hline 13 & & Renda média mensal & $\begin{array}{l}\text { De } R \$ 1.000,00 \mathrm{a} \\
\mathrm{R} \$ 3.000,00\end{array}$ & $16(46,00 \%)$ \\
\hline
\end{tabular}




\begin{tabular}{|c|c|c|c|c|}
\hline 14 & \multirow{5}{*}{$\begin{array}{l}2 . \\
\text { Habilidades }\end{array}$} & Turma & $\begin{array}{l}2020-1^{\circ} \text { semestre } \\
\text { (ingressantes) }\end{array}$ & $19(56,00 \%)$ \\
\hline 15 & & Fluência em idioma & Português & $26(79,00 \%)$ \\
\hline 16 & & $\begin{array}{l}\text { A fluência se deu por meio das } \\
\text { disciplinas ofertadas no curso }\end{array}$ & Não & $28(86,00 \%)$ \\
\hline 17 & & Conhecimentos de TIC & Intermediário & $20(58,00 \%)$ \\
\hline 18 & & $\begin{array}{l}\text { O nível de conhecimento se deu por } \\
\text { meio da disciplina ofertada no } \\
\text { curso }\end{array}$ & Não & $28(82,00 \%)$ \\
\hline 19 & \multirow{7}{*}{$\begin{array}{l}3 . \\
\text { Informações sobre } \\
\text { o curso }\end{array}$} & $\begin{array}{l}\text { Por que decidiu trabalhar na área de } \\
\text { eventos }\end{array}$ & $\begin{array}{l}\text { Porque a área me } \\
\text { permite ter dias } \\
\text { livres para } \\
\text { organizar minha } \\
\text { vida pessoal }\end{array}$ & $9(60,00 \%)$ \\
\hline 20 & & $\begin{array}{l}\text { Por que decidiu cursar o Curso } \\
\text { Técnico Subsequente em Eventos } \\
\text { no IFPR }\end{array}$ & $\begin{array}{l}\text { Porque eu gosto da } \\
\text { área de eventos }\end{array}$ & $24(70,00 \%)$ \\
\hline \multirow{3}{*}{21} & & \multirow{3}{*}{$\begin{array}{l}\text { Como você pretende atuar, } \\
\text { profissionalmente, após a conclusão } \\
\text { do curso considerando os } \\
\text { conhecimentos adquiridos no Curso } \\
\text { Técnico Subsequente em Eventos, } \\
\text { até o momento }\end{array}$} & $\begin{array}{l}\text { Eventos } \\
\text { sociais/coloquiais }\end{array}$ & $9(27,00 \%)$ \\
\hline & & & $\begin{array}{l}\text { Habilidades não } \\
\text { adquiridas no curso }\end{array}$ & $3(9,00 \%)$ \\
\hline & & & Empreendendo & $6(18,00 \%)$ \\
\hline 22 & & $\begin{array}{l}\text { Discentes que responderam possuir } \\
\text { ensino superior, porque decidiram } \\
\text { fazer um Curso Técnico } \\
\text { Subsequente em Evento no IFPR }\end{array}$ & $\begin{array}{l}\text { Porque pretendo ter } \\
\text { uma qualificação } \\
\text { específica na área }\end{array}$ & $9(60,00 \%)$ \\
\hline 23 & & $\begin{array}{l}\text { Discentes que tem interesse em } \\
\text { participar de seleção para pós- } \\
\text { graduação Lato Sensu em eventos }\end{array}$ & $\begin{array}{l}\text { Sim (ensino } \\
\text { superior completo) }\end{array}$ & $13(97,00 \%)$ \\
\hline
\end{tabular}

Fonte: Dados da pesquisa (2021).

A discussão dos resultados será realizada com base nas análises e interpretações apresentadas e balizadas pelo quadro resumo 3 , debatendo as variáveis e direcionando a checagem dos objetivos específicos apresentados na introdução deste estudo. Por fim, serão confirmadas ou refutadas as hipóteses levantadas.

1) Conhecer a realidade sociodemográfica dos discentes do curso: se comparado ao estudo do INEP (2019) confirma-se tendência de maioria das discentes do curso serem gênero feminino, na faixa etária entre 18 e 29 anos, sendo a realidade do curso, 17 e 24 anos. Como não era interesse deste estudo análises de raça, não se segmentou estes dados.

Ao ampliarmos o estudo do INEP (2019) percebe-se que as discentes são solteiras, o que pode ter duas fortes relações: com a faixa etária (jovens) e, com o fato de o curso ser realizado no período noturno. Estas residem em Curitiba e quando residem em RM são, na maioria de São José do Pinhais. Município da RM mais próximo ao Campus Curitiba, o que se justifica devido ao curso ser presencial. Estas têm ensino médio completo que se comparado a maioria da faixa etária apresentada, estas buscaram alternativas para continuar os estudos pós- 
médio reforçando a teoria de Kuenzer (2001) sobre os cursos técnicos serem "substitutos ao ensino superior".

Mesmo que a maioria das discentes tenha ensino médio completo, verificou-se que 14 $(41,00 \%)$ dos discentes, de ambas as turmas têm formação em ensino superior e quando analisada a área de formação, a maioria se formou em publicidade e propaganda, o que confirma os dados da pesquisa de Aquino e Teles (2019) para formação profissional dos promotores de eventos de Curitiba e RM. Formação profissional esta que está diretamente relacionada à produção de eventos, por ser uma atividade complementar e permitir atuação na área por sua grade curricular ter disciplinas dedicada a eventos.

Estas discentes não trabalham com eventos e veem como oportunidade fazer o curso como uma alternativa de inserção neste mercado. Dos poucos que afirmaram trabalhar com eventos, a maioria trabalha na área de produção, confirmando novamente Aquino e Teles (2019), porém, estas têm 1 a 5 anos na função, 5 anos de experiência a menos, do que o levantado pelas autoras.

Entre os que não trabalham com eventos se destacaram os profissionais de administrativa/financeira/RH (auxiliares ou analistas) confirmando mais uma vez estudo de Aquino e Teles (2019) sobre a atividades profissionais pregressas dos promotores de eventos de Curitiba e RM. Porém, estas, majoritariamente, são contratados por CLT, condição profissional de contratação formal e assegurada por documentação legal e, têm renda mensal entre $R \$ 1.000,00$ e 3.000,00, valor que compreende a média obtida pelos resultados das autoras. Destaca-se o grande número de desempregadas, fato que se justifica pela crise econômica mundial gerada pela pandemia de COVID-19, no período de realização desta pesquisa.

2) Examinar se os conteúdos curriculares e abordagens disciplinares do PPC vigente estão de acordo com a realidade apresentada pelos discentes: a fluência em idioma português que não foi apreendido por meio de disciplina ofertada no curso se deve a falha de interpretação da questão e contradiz a alteração do PPC (2014). No novo PPC (2019) manteve-se o idioma espanhol, neste sentido, comparando aos PPC's de todos os cursos Técnicos Subsequentes em Eventos dos IF's apresentados, o investimento deveria ser no idioma inglês, para atender as exigências de mercado. Este dado se confirma quando apenas 1 (3,00\%) dos respondentes desta questão afirmou que têm fluência em inglês, por ter sido a variável de menor índice deve-se investir em manter este componente curricular (IFPR, 2014, 2019). 
A respeito da TIC de nível intermediário entre os discentes, percebeu-se que esta tornase dispensável ao curso e devia-se manter a disciplina focando os conhecimentos para o nível avançados. Se comparado aos PPC's de todos os cursos Técnicos Subsequentes em Eventos dos IF's apresentados, refuta-se a alteração do PPC (2019). O Office (Excel) em nível avançado é conhecimento fundamental à área de eventos devido às inúmeras planilhas que devem ser confeccionadas a saber: check list, cronograma, planejamento de eventos, controle financeiros e relatórios gerais que estes manipulam (PPC, 2019).

Ratificou-se mais uma vez os dados de Aquino e Teles (2019) quando os discentes responderam que decidiram trabalhar na área de eventos devido à possibilidade de dias livres para organização pessoal. Já que os eventos são realizados por contratos, empreitadas (projetos) ou por dia, estes entendem esta como oportunidade de organização pessoal.

Quanto ao motivo de trabalharem na área a resposta é óbvia, afinal, não se busca um curso para se qualificar numa área profissional que não se gosta ou que não se tenha afinidade ou interesse de aprofundamento.

Ao compararmos a quantidade de discentes por Turma, em relação aos dados apresentados no PPC (2019), percebe-se que a Turma 2019 tem 5 (27,78\%) discentes concluintes a mais que os concluintes da Turma 2018 e, este aumento na procura pelo curso atribui-se a dois fatores:

1) os sorteios de vagas remanescentes após a realização do concurso e;

2) não ter outro curso gratuito em eventos de nível técnico ou pós-graduação Lato Sensu em Curitiba e RM. A Turma 2020 representa um aumento de 6 (26,08\%) discentes a mais que a Turma 2019, mas, ainda não se pode garantir que todos chegarão a se formar devido à evasão motivada pela pandemia de COVID-19. De qualquer maneira, a Turma 2020, está entre as maiores Turmas que o Curso Técnico Subsequente em Eventos do IFPR - Campus Curitiba já teve, perdendo apenas para os concluintes da Turma de 2015, com 38 discentes formados (IFPR, 2019).

3) Identificar a presença de demandas para desdobramentos de novas propostas formativas: os discentes pretendem atuar, profissionalmente, após a conclusão do Curso Técnico Subsequente em Eventos em três importantes pilares: 1) com eventos sociais e coloquiais, assim, seria interessante facilitar esta inserção profissional ofertando um componente curricular que abordasse exclusivamente esta temática visto que segundo CC\&VB (2014), os eventos sociais ainda representam baixos índices de realização em Curitiba e RM, 
tendo bom potencial de crescimento; 2) em relação às habilidades não adquiridas demonstra que estes estão em busca de novos conhecimentos e novas formações e que pretendem investir na formação continuada, o que já demonstra forte interesse em pós-graduações Lato Sensu na área; 3) quanto a pretensão de se tornarem empreendedores, se comparado as respostas das questões 12 e 13, já se percebe o perfil empreendedor dos discentes. Neste sentido, seria especialmente interessante focar em ter um componente curricular que abordasse exclusivamente empreendedorismo e, não como o tema é abordado no PPC vigente ou o novo, agregado ao componente curricular de Gestão Financeira e Captação de Recursos para Eventos (IFPR, 2014 , 2019). Este componente curricular já é ofertado nos cursos Subsequentes dos IF's de MG, SP - Avaré e Barretos, Ceará, SC e Fluminense - Cabo Frio e Campos Centro (IFSP, 2012, 2014; IFFluminense, 2012; IFCE, 2015; IFMG, 2016; IFSP, 2016; IFSC, 2017). Neste sentido, orienta-se que sejam realizadas atualizações no PPC (2019) quanto ao perfil do profissional de conclusão. Sugere-se a inserção de um novo tópico afirmando que o curso prepara os discentes para empreenderem e gerirem seus próprios negócios no segmento de eventos gerando oportunidades profissionais e de mercado.

Sugere-se que seja incluído o componente curricular de Elaboração de Projeto, conforme os cursos Técnicos Subsequentes em Eventos do IFSP Campus Barretos e IFFarroupilha - Campus São Borja (IFSP, 2012; IFFarrouopilha, 2014).

Os discentes afirmam que buscavam uma qualificação específica na área, por isso tiveram interesse em realizar o curso, considerando que $41,00 \%$ destes respondentes têm formação em ensino superior e, são o público-alvo de oferta de pós-graduação, o que estes buscavam era um curso de pós-graduação Lato Sensu para se especializarem em eventos. Destes 97,00\% afirmam que teriam interesse em cursar uma oferta de pós-graduação Lato Sensu (especialização) em eventos, o que se confirma a oportunidade de abertura para uma nova demanda formativa na instituição com desmembramento do curso técnico já existente, com quase $100,00 \%$ de certeza pode-se afirmar êxito nesta empreitada. Logo, sugere-se ao colegiado do Curso Técnico Subsequente em Eventos deste IFPR e a Direção do Campus que considere a alternativa de implantação de um novo curso de pós-graduação em sintonia com as expectativas e demandas da comunidade acadêmica e que foram documentadas nesta pesquisa.

Por fim, ressalta-se o alinhamento do perfil sociodemográfico e profissional dos promotores de eventos de Curitiba de RM apresentado por Aquino e Teles (2019) com o perfil analítico dos discentes do Curso Técnico Subsequente em Eventos do IFPR - Campus Curitiba: 
Turmas 2019 e 2020 e, que os profissionais formados pelo curso têm as mesmas condições profissionais do perfil apresentado pelas autoras e ainda, apresentam o diferencial da formação profissional na área, por este motivo, deveriam ocupar este espaço no mundo do trabalho. Atribui-se a não inserção destes profissionais na oferta da área em Curitiba e RM à falta de articulação entre o curso e às associações, aos sindicatos e aos órgãos representantes do segmento, conforme Portaria $n^{\circ} 646$ de 1997 no art. $7^{\circ}$ que dispõem que a oferta de cursos de nível técnico e de qualificação devem ser demandas identificadas de acordo com setores produtivos (BRASIL,1997b). Tal situação confirma a ação do colegiado em desenvolver um projeto de extensão intitulado de: "Fortalecimento do Curso Técnico Subsequente em Eventos junto ao mundo do trabalho" paralelo, conforme objetivo mencionado na introdução, mas, infelizmente, devido a pandemia de COVID-19 este teve sua execução suspensa.

Destacar-se, caso as alterações fossem realizadas no PPC (2014), o curso deveria se manter com duração de 1 ano de 6 meses, acompanhando os PPC's dos demais cursos Técnicos Subsequentes em Eventos dos IF's apresentados no quadro 2. Assim, sugere-se que o colegiado do curso ciente dos resultados aqui apresentados possa deliberar sobre este tema em futuras atualizações do PPC do Curso de Técnico Subsequente em Eventos deste IFPR - Campus Curitiba.

Por fim, todas as hipóteses foram confirmadas, apenas a maioria de discentes com formação em ensino superior foi refutada, mas, considerou-se um número expressivo para análise das proposições:

A maioria dos discentes do Curso Técnico Subsequente em Eventos do IFPR - Campus Curitiba já têm uma formação superior e, tiveram o interesse em fazer um curso de nível técnico: não são a maioria dos discentes com formação em ensino superior, estes representam $41,00 \%$ dos discentes participantes da pesquisa. Dois desmembramentos de análise podem ser feitos aqui, visto que: 1) a maioria de discentes estão na faixa etária entre 17 e 24 anos e possuem o ensino médio, o que demonstra uma possibilidade de adequação de currículo para ofertar o curso em nível de graduação, ou ainda; 2) para atender a este público expressivo 97,00\% dos discentes que tem ensino superior e tem interesse em se qualificar na área de eventos, elaborar oferta para um curso em pós-graduação Lato Sensu (especialização).

O desejo de se especializarem na área de eventos confirma as proposições acima por ser um curso gratuito que irá ampliar as oportunidades de inserção no mercado profissional, e ainda, pela baixa oferta de especializações gratuitas na área, em nível de pós-graduação Lato Sensu, 
na urbe de Curitiba e RM: O desejo de se especializarem na área de eventos se confirma não apenas pela afirmação dos discentes, mas, pelas áreas de formação que estes possuem ensino superior, áreas correlatas e complementares que demandam conhecimentos específicos à área de eventos.

\section{CONSIDERAÇÕES FINAIS}

Foi possível detectar falhas na marcação de opções das questões devido à ferramenta de tabulação utilizada, mas, mesmo que os participantes tenham interpretado algumas questões de forma equivocada, ao realizar o cruzamento dos dados, encontrou-se neste, um recurso eficaz para validá-los e descartou-se as falhas de interpretação.

Com a confirmação de maioria das hipóteses levantadas faz-se a proposição de um planejamento estratégico do curso com maior eficiência, aplicando as melhorias adequadas às realidades identificadas implementando no PPC vigente (2014) e, o PPC novo (2019), não deveria ter entrado em vigor. Assim, conforme quadro 4 a seguir a estrutura sintética para adequação dos componentes curriculares do Curso Técnico Subsequente em Eventos do IFPR - Campus Curitiba, mantendo-o com duração de 1 ano e 6 meses:

Quadro 4 - Proposta de Matriz Curricular para o Curso Técnico Subsequente em Eventos do IFPR - Campus Curitiba com base no Perfil Analítico dos discentes das Turmas 2019 e 2020

\begin{tabular}{|c|c|c|}
\hline Componentes curriculares & Semestre & Carga horária \\
\hline Segurança e Operacionalização em Eventos & \multirow{7}{*}{$\mathbf{1}^{\mathbf{o}}$} & $40 \mathrm{~h}$ \\
\hline Introdução a Projetos e Planejamento de Eventos & & $80 \mathrm{~h}$ \\
\hline Introdução ao Turismo e Hospitalidade & & $40 \mathrm{~h}$ \\
\hline TIC & & $40 \mathrm{~h}$ \\
\hline Psicologia das Relações Humanas & & $40 \mathrm{~h}$ \\
\hline Cerimonial, Protocolo e etiqueta & & $40 \mathrm{~h}$ \\
\hline Laboratório de Eventos I - Eventos Sociais e Coloquiais & & $40 \mathrm{~h}$ \\
\hline Marketing de Eventos & \multirow{6}{*}{$\mathbf{2}^{\mathbf{o}}$} & $40 \mathrm{~h}$ \\
\hline Comunicação e Expressão em Língua Inglesa & & $80 \mathrm{~h}$ \\
\hline Comunicação e Expressão em Língua Portuguesa & & $40 \mathrm{~h}$ \\
\hline Gestão Financeira e Captação de Recursos para Eventos & & $80 \mathrm{~h}$ \\
\hline Alimentos e Bebidas & & $40 \mathrm{~h}$ \\
\hline Laboratório II - Eventos Dialogais & & $40 \mathrm{~h}$ \\
\hline Legislação Aplicada a Eventos & \multirow{7}{*}{$3^{\mathbf{o}}$} & $40 \mathrm{~h}$ \\
\hline Estratégia de Mídias e Comunicação & & $40 \mathrm{~h}$ \\
\hline Planejamento Sustentável de Eventos & & $40 \mathrm{~h}$ \\
\hline Espaços e Layouts & & $40 \mathrm{~h}$ \\
\hline Empreendedorismo & & $40 \mathrm{~h}$ \\
\hline Elaboração de Projeto & & $40 \mathrm{~h}$ \\
\hline Laboratório III - Competitivos e Expositivos/Demonstrativos & & $40 \mathrm{~h}$ \\
\hline TOTAL & & $960 \mathrm{~h}$ \\
\hline
\end{tabular}

Fonte: Dados da pesquisa (2021) com base no PPC (2014). 
Os componentes curriculares da oferta seriam os mesmos dos PPC (2014), mantendo TIC e Comunicação e Expressão em Língua Inglesa, fazendo alteração apenas no $3^{\circ}$ período, retirando Comunicação e Expressão em Língua Espanhola, que é um componente curricular de 80 h, redistribuindo horas em 40 h, para cada componente ofertando: Empreendedorismo e Elaboração de Projeto. Os componentes de Laboratório I, II e III deveria focar na execução dos tipos de eventos que os discentes demonstraram interesse de área a trabalhar no mercado pósformação, começando com Laboratório I - Eventos Sociais e Coloquiais, Laboratório de Eventos II - Eventos Dialogais e Laboratório de Eventos III - Competitivos e Expositivos/Demonstrativos, de acordo com as tipologias de eventos da CNI (2005). Assim, o curso se manteria com a duração de 1 ano e 6 meses, conforme os PPC's dos cursos Técnicos Subsequente em Eventos dos IF's estudados.

Caso, opte-se pela oferta de curso em nível de pós-graduação Lato Sensu, sugere-se retirar a oferta dos componentes de idiomas, mas, deve-se manter TIC's. As proposições para construção de uma matriz curricular para esta oferta deveriam acompanhar os PPC's dos cursos de pós-graduação Lato Sensu em Eventos, para cumprir exigências conteúdos de formação profissional. Da mesma forma, caso opte-se por oferta de um curso em nível de graduação.

Por fim, afirma-se que este estudo não se encerra em si, tendo oportunidades de aprofundamento em análises. Neste ponto, declara-se que os autores não têm nenhum conflito de interesse na investigação do tema e, que o intuito deste estudo é apresentar informações de base científica, para o planejamento estratégico do Curso Técnico Subsequente em Eventos do IFPR - Campus Curitiba conforme motivado pela Semana Pedagógica - Formação Pedagógica e Planejamento Coletivo Edição 2020.

\section{REFERÊNCIAS}

ANDRADE, Francisca Rejane Bezerra; CRUZ, Juliane Barros. Juventudes e Educação Profissional: um estudo de caso junto aos jovens que cursam o ensino médio integrado ao ensino técnico no IFCE - Campus Fortaleza. Educação e Emancipação, São Luís , v. 9, n. 3, p. 39-61, Edição Especial 2016.

ARAÚJO, Ronaldo Marcos de Lima; RODRIGUES, Doriedson do Socorro. Referências sobre práticas formativas em Educação Profissional: o velho travestido de novo ante o efetivamente novo. In: ARAÚJO, Ronaldo Marcos de Lima; RODRIGUES, Doriedson do Socorro. (Org.). Filosofia da práxis e dialética da educação profissional. Campinas, SP: Autores Associados, 2011. p. 7 - 45, v. 1.

AQUINO, Mayna de; TELES, Margarete Araujo. (2019). Análise do perfil sociodemográfico e profissional do Promotor de eventos de Curitiba e Região Metropolitana (Paraná, Brasil). 
Revista de Turismo Contemporâneo, 7, Edição Especial, 85-103. DOI: https://doi.org/10.21680/2357-8211.2019v7n0ID16911.

BRASIL. Instituto Nacional de Estudos e Pesquisas Educacionais Anísio Teixeira (Inep). Censo da Educação Básica 2019: Resumo Técnico. Brasília, 2020. Disponível em: http://portal.inep.gov.br/documents/186968/484154/RESUMO+T\%C3\%89CNICO++CENSO+DA+EDUCA\%C3\% 87\%C3\%830+B\%C3\%81SICA+2019/586c8b06-7d 83-4d699e1c-9487c9f29052?version=1.0. Acesso em: 20 out. 2020.

BRASIL. Ministério da Educação. Centenário da Rede Federal de Educação Profissional e Tecnológica, 2009. disponível em:

http://portal.mec.gov.br/setec/arquivos/centenario/historico_educacao_profissional.pdf. Acesso em: 21 out. 2020.

BRASIL. Portaria $\mathbf{n}^{\mathbf{0}}$ 646, de 14 de maio de 1997. Regulamenta a implantação do disposto nos artigos 39 a 42 da Lei Federal nº 9.394/96 e no Decreto Federal n 2.208/97 e dá outras providências (trata da Rede Federal de educação tecnológica). Diário Oficial da União, Brasília, 15 mai. 1997b.

BRASIL, Lei $\mathbf{n}^{\mathbf{0}}$ 11.741, de 16 de julho de 2008. Estabelece as diretrizes e bases da educação nacional, para redimensionar, institucionalizar e integrar as ações da educação profissional técnica de nível médio, da educação de jovens e adultos e da educação profissional e tecnológica. Diário Oficial da União, Brasília, 16 jul. 2008. 2008a. Disponível em: http://www.planalto.gov.br/ccivil_03/_ato2007-2010/2008/lei/111741.htm. Acesso em: 22 ago. 2020.

BRASIL. Lei $\mathbf{n}^{\circ}$ 11.892, de 29 de dezembro de 2008. Institui a Rede Federal de Educação Profissional, Científica e Tecnológica, cria os Institutos Federais de Educação, Ciência e Tecnologia, e dá outras providências. Diário Oficial da União, Brasília, p. 1, 30 dez. 2008. 2008b. Disponível em: http://www.planalto.gov.br/ccivil 03/ ato20072010/2008/lei/111892.htm. Acesso em: 03 nov. 2020.

BILERT, Vania Souza; BISCOLI, Fabian Veloso. Perfil dos discentes (ingressantes e concluintes) de secretariado executivo: um estudo comparativo nas instituições de ensino superior (IES) públicas. Revista de Gestão e Secretariado, São Paulo, v. 2, n. 2, p.33-57, jul./dez. 2011.

BOSCARDIN, Jardel; PAIM, Aline Ferreira; RORATO, Daniele Guarienti; CERA, Jossana Ceolin; MAZIERO, Sandra Maria e; PEREIRA, Ascísio dos Reis. Aspectos do perfil discente do curso técnico em paisagismo da Universidade Federal de Santa Maria. Rev. Gest. Aval. Educ. Santa Maria v. 5 n. 9 Jan./jun. 2016, p. 21-30.

CARVALHO, William Ladeia de.; REJOSWKI, Mirian. Tecnologia em eventos da Faculdade Hotec, São Paulo: proposta de formação versus atuação profissional de egressos. Revista Hospitalidade. São Paulo, v. IX, n. 1, p. 82 - 104, junho 2012.

CRESWELL, John W. Projeto de pesquisa: métodos qualitativos, quantitativos e mistos. (3a. ed.). Porto Alegre: Artmed, 2010. 
CRESWELL, John W. Investigação qualitativa e projeto de pesquisa. Porto Alegre: Penso Editora LTDA, 2014.

CONFEDERAÇÃO NACIONAL DA INDÚSTRIA. Manual de Eventos. Brasília: CNI, 2005.

CUNHA, Luiz Antônio. O ensino profissional na irradiação do industrialismo. São Paulo: UNESP; Brasília: Flacso, 2000.

CURITIBA CONVENTION \& VISITORS BUREAU. Relatório de Gestão 2011-2014. Curitiba Região e Litoral, 2014. Disponível em:

http://www.curitibacvb.com.br/ckfinder/userfiles/files/Relat\%C3\%B3rio(1).pdf. Acesso em: 09 nov. 2020.

INSTITUTO FEDERAL DE SÃO PAULO (IFSP) - Campus Avaré. Projeto Pedagógico Curso Técnico em Eventos. Avaré, 2012. Disponível em:

https://avr.ifsp.edu.br/images/pdf/Eventos/PPC\%20EVENTOS\%20CONCOMITANTE.pdf. Acesso em: 23 out. 2020.

INSTITUTO FEDERAL DE SÃO PAULO (IFSP) - Campus Barretos. Projeto Pedagógico Projeto Pedagógico do Curso Técnico Em Eventos Concomitante/Subsequente. Barretos, 2014. Disponível em:

https://brt.ifsp.edu.br/phocadownload/userupload/202599/PPC Eventos Barretos Versao De z_2016.pdf. Acesso em: 23 out. 2020.

INSTITUTO FEDERAL FARROUPILHA (IFFARROUPILHA) - Campus São Borja. Projeto Pedagógico do Técnico em Eventos Integrado. São Borja, 2020. Disponível em: https://www.iffarroupilha.edu.br/component/k2/attachments/download/315/92104ed8c026eeb b1e0a95d654a8b1ea. Acesso em: 23 out. 2020.

INSTITUTO FEDERAL FARROUPILHA (IFFARROUPILHA) - Campus São Borja. Projeto Pedagógico Do Curso Técnico em Eventos Subsequente. São Borja, 2014. Disponível em:

https://www.iffarroupilha.edu.br/component/k2/attachments/download/316/086cb68b49930b 9e5027def94ecde21c. Acesso em: 23 out. 2020.

INSTITUTO FEDERAL FLUMINENSE (IFFLUMINENSE) - Campus Campos Centro e Cabo Frio. Projeto Pedagógico Curso Técnico em Eventos na modalidade a Distância. Campos Centro e Cabo Frio, 2012. Disponível em: http://portal1.iff.edu.br/nossoscampi/campos-centro/cursos/educacao-a-distancia/tecnico-em-eventos-na-modalidade-daeducacao-a-distancia/ppc_eventos.pdf. Acesso em: 23 out. 2020.

INSTITUTO FEDERAL Do CEARÁ (IFCE) - Campus Aracaú. Projeto Pedagógico de Curso Técnico em Eventos. Aracaú, 2015. Disponível em:

https://ifce.edu.br/acarau/menu/cursos/tecnicos/subsequentes/eventos/pdf/ppc-deeventos.pdf/@@download/file/ppc\%20de\%20eventos.pdf. Acesso em: 23 out. 2020.

INSTITUTO FEDERAL DE MINAS GERAIS (IFMG) - Campus Belo Horizonte. Projeto Pedagógico de Curso Técnico Em Eventos. Belo Horizonte, 2016. Disponível em: https://www2.ifmg.edu.br/portal/extensao/pronatec/cursos/cursos-tecnicos/projeto- 
pedagogico-de-curso-tecnico-emeventos/@@download/file/PPC\%20T\%C3\%A9cnico\%20em\%20Eventos.pdf. Acesso em: 23 out. 2020.

INSTITUTO FEDERAL DO PARANÁ (IFPR) - Campus Curitiba. História. Curitiba, 2019. Disponível em: https://reitoria.ifpr.edu.br/institucional/o-instituto/historia/. Acesso em: 23 out. 2020.

INSTITUTO FEDERAL DO PARANÁ (IFPR) - Campus Curitiba. PPC - Projeto Pedagógico do Curso Técnico em Eventos. Curitiba, 2019. Disponível em:

https://curitiba.ifpr.edu.br/wp-content/uploads/2021/02/1.-PPC-T\%C3\%A9cnico-em-Eventos2020.pdf. Acesso em 08 fev. 2021.

INSTITUTO FEDERAL DO PARANÁ (IFPR) - Campus Curitiba. PPC - Projeto Pedagógico do Curso Técnico em Eventos. Curitiba, 2014. Disponível em: http://curitiba.ifpr.edu.br/wp-content/uploads/2010/12/PPC-2014-Curso-T\%C3\%A9cnicoem-Eventos-Reformulado.pdf. Acesso em 03 set. 2020.

INSTITUTO FEDERAL DO RIO GRANDE DO SUL (IFRS) - Campus Osório. Projeto Pedagógico do Curso Técnico em Eventos Subsequente ao Ensino Médio. Osório, 2019. Disponível em: https://ifrs.edu.br/osorio/tecnico-em-eventos/ppc-eventos-08-02-2019-versaofinal-1/. Acesso em: 23 out. 2020.

INSTITUTO FEDERAL DE SANTA CATARINA (IFSC) - Campus FlorianópolisContinente. Projeto Pedagógico de Curso Técnico em Eventos. Florianópolis, 2017. Disponível em: https://sig.ifsc.edu.br/sigaa/verProducao?idProducao=138689\&key=407117ec9d7c01f8dc135 231f59b0c3e. Acesso em: 23 out. 2020.

INSTITUTO FEDERAL DO TOCANTINS (IFTO) - Campus Palmas. Matriz curricular do Curso Técnico em Eventos. Palmas, 2015. Disponível em:

http://www.ifto.edu.br/palmas/campus-palmas/cursos-palmas/tecnicos/integradoregular/tecnico-em-eventos/grade-curricular/grade-curricular-ti-eventos.pdf/view. Acesso em: 23 out. 2020.

INSTITUTO FEDERAL DO RIO GRANDE DO NORTE (IFRN) - Campus Canguaretama. Projeto Pedagógico do Curso Técnico de Nível Médio em Eventos. Natal, 2014.

Disponível em: https://portal.ifrn.edu.br/ensino/cursos/cursos-tecnicos-de-nivelmedio/tecnico-integrado/tecnico-em-eventos/at_download/coursePlan. Acesso em: 23 out. 2020.

KUENZER, Acácia Zeneida. (Org.). Ensino Médio: construindo uma proposta para os que vivem do trabalho. São Paulo: Cortez, 2000.

KUENZER, Acácia Zeneida. Ensino médio e profissional: as políticas do Estado neoliberal. 3.ed. São Paulo: Cortez, 2001

LINS, Maria Judith Sucupira da Costa; MIYATA, Edson Seiti. Avaliando a aprendizagem de criatividade em uma oficina pedagógica. Ensaio: Avaliação e Políticas Públicas em Educação, Rio de Janeiro, v.16, n.60, jul./set. 2008, p.455-468 
MACHADO, Maria Lucia Büher. Formação profissional e modernização no Brasil (19301960): uma análise à luz das reflexões teórico-metodológicas de Lucie Tanguy. Educ. Soc. [online]. 2012, vol.33, n.118, pp.97-114. ISSN 1678-4626. DOI:

https://doi.org/10.1590/S0101-73302012000100007.

MENDONÇA, Aline Graciele. Ensino técnico de nível médio: momentos de prestígio e de esquecimento se alternando durante a história da educação profissional no Brasil. Horizontes, Bragança Paulista, v.32, n.2, p. 87-99, jul./dez. 2014.

MOTTA, Paulo Tadeu Rabelo da. O perfil do aluno de cursos técnicos ou parem as máquinas: o aluno envelheceu. Revista EIXO, Brasília - DF, v.3 n.2, julho - dez. 2014.

MORAZ, Caterine Pereira. A formação profissional: trajetórias e expectativas dos estudantes dos cursos técnicos subsequentes. 2015. 197 f. Dissertação (Mestrado) Programa de Pós-Graduação em Tecnologia. Área de Concentração: Tecnologia e Sociedade, Universidade Tecnológica Federal do Paraná, Curitiba, 2015. Disponível em: http://repositorio.utfpr.edu.br/jspui/bitstream/1/2613/1/CT PPGTE M Moraz\%2C\%20Cateri ne\%20Pereira_2016..pdf. Acesso em: 26 fev. 2020.

MOURA, Dante Henrique. Educação básica e educação profissional e tecnológica: dualidade histórica e perspectiva de integração. Holos, Natal, ano 23, v.2, 2007. Disponível em: http://www2.ifrn.edu.br/ojs/index.php/HOLOS/ar;cle/viewFile/11/110. Acesso em: 30 out. 2017.

Rede CAFe federado IFPR. Disponível em: https://shibboleth.ifpr.edu.br/idp/profile/SAML2/Redirect/SSO. Acesso em: 05 de mai. 2020.

ROCHA-PINTO, Sandra Regina da; BEZERRA, Kátia Regina. Desenvolvimento de competências em escolas técnicas: as visões de contratados e contratantes. Administração: Ensino e Pesquisa, Rio de Janeiro, v.15, n.2, p. 351-379, abr./jun. 2014.

SILVA, Mariléia Maria da; GUEDES, Thaís. Formação dos trabalhadores para o capital: uma análise de projetos pedagógicos de cursos técnicos subsequentes do IFSC, campus Florianópolis. Educação \& Formação, Fortaleza, v. 3, n. 3, set./dez. 2018, p. 102-120

SOARES, Maria Lúcia da Silva. O mercado profissional do turismo e os egressos do Curso Técnico Subsequente em Eventos do Instituto Federal de Educação, Ciência e Tecnologia do Pará - IFPA/Campus Belém. 2012. 163 f., il. Dissertação (Mestrado em Educação) —Universidade de Brasília, Brasília, 2012.

SOUZA, Helck Rosita Garcia Prudencio de, MARTINS, Luiz Ailil Vianna, MAIOLI, Marcos Rogério. Acompanhamento Dos Estudantes Egressos do Curso Técnico Em Eventos Na Modalidade Subsequente do Instituto Federal do Paraná - Campus Curitiba. . 13 Fórum Internacional de Turismo do Iguassu. 12 a 14 jun. 2019. Foz do Iguaçu, Paraná. Disponível em: https://www.sisapeventos.com.br/deangeli/wiew/anais/event/1.

SURVEY MONKEY - Calculadora de margem de erro. Disponível em: https://wwwencurtador.com.br/buxH4. Acesso em 26 ago. 2020. 
XAVIER, Thays Ribeiro Torres Magalhães; FERNANDES, Natal Lânia Roque. Educação Profissional Técnica integrada ao ensino médio: considerações históricas e princípios orientadores. Revista de Estudos e Pesquisas Sobre o Ensino Tecnológico, Manaus, v. 05, n. 11, p. 101-113, abr./jun. 2019.

\section{Agradecimentos}

Ao IFPR - Campus Curitiba, ao Comitê de Ética em Pesquisa do IFPR e ao Comitê de Pesquisa e Extensão do IFPR - Campus Curitiba por autorizarem a realização deste estudo.

Aos 34 discentes que se voluntariaram a participar da pesquisa, para obtenção dos dados que permitiu a construção deste perfil.

À Prof ${ }^{a}$. Me. Celia Regina Celli, professora substituta de língua portuguesa e espanhol do IFPR - Campus Curitiba, por ter realizado a correção gramatical e ortográfica deste artigo. 